Check for updates

Cite this: RSC Adv., 2019, 9, 35209

Received 10th September 2019 Accepted 24th October 2019

DOI: $10.1039 / c 9 r a 07263 b$

rsc.li/rsc-advances

\section{Adsorption-desorption behavior of carbendazim by sewage sludge-derived biochar and its possible mechanism $\uparrow$}

\begin{abstract}
Tengda Ding, (D) *a Tuo Huang, ${ }^{a}$ Zhenhua Wu, ${ }^{b}$ Wen $\mathrm{Li}^{a}{ }^{a}$ Kexin Guo ${ }^{c}$ and Juying $\mathrm{Li}^{(\mathbb{D}}{ }^{\mathrm{a}}$
Biochar application in agricultural soil for environmental remediation has received increasing attention, however, few studies are focused on sewage sludge based biochar. The present study evaluated the effect of raw sewage sludge and sewage sludge based biochars produced at different pyrolysis temperatures $\left(100-700^{\circ} \mathrm{C}\right)$ on the adsorption-desorption of carbendazim in soil. Sewage sludge derived biochar significantly enhanced the sorption affinity and limited the desorption capacity of the soil for carbendazim. A maximum removal efficiency of $98.9 \%$ and a greatest value of $144.05 \pm 0.32 \mu \mathrm{g} \mathrm{g}^{-1}$ sorption capacity occurred in soil amended with biochar pyrolyzed at $700{ }^{\circ} \mathrm{C}(\mathrm{BC} 700)$. As the pyrolysis temperature and the amendment rate of biochars increased, the sorption of carbendazim was promoted and desorption was further inhibited. The adsorption-desorption hysteresis index of carbendazim was consistently higher in soils amended with biochars (>0.85) than in the unamended soil $(0.42-0.68)$, implying that carbendazim could be immobilized in soil amended with sewage sludge derived biochars. The partition effect was dominant in the sorption process for carbendazim in the biochar-soil mixtures. This study will be helpful for the disposal of sewage sludge and its utilization, and it is the first report for the study the sorption-desorption process of carbendazim in soil amended with sewage sludge derived biochar. Furthermore, these findings may be also useful for understanding the distribution and transport of carbendazim in the environment and will be of great significance in remediation strategies for contaminated soil.
\end{abstract}

\section{Introduction}

Carbendazim is a widely used benzimidazole fungicide for plant disease control, ${ }^{1}$ and has been identified as a toxic class IV pesticide because of its toxic effects to human health and the environment. ${ }^{2}$ Andrade et al. reported that carbendazim posed developmental anomalies in zebrafish embryos with $\mathrm{EC}_{50}$ values ranging from 0.85 to $1.6 \mathrm{mg} \mathrm{L}^{-1}$. ${ }^{3}$ Singh et al. found that carbendazim can disrupt the structure of microbial communities in soil. ${ }^{4}$ Moreover, it was found to be very resistant to degradation $\left(t_{1 / 2}=154 \mathrm{~d}\right)$ in soil, leading to a high accumulation in crops and extensive public concerns. ${ }^{5}$

Biochar is a carbon-rich material from biomass pyrolysis under oxygen-limited conditions. Application of biochars in soil is attracting worldwide interest and has been proposed as an appealing approach for mitigating global warming, because

${ }^{a}$ College of Chemistry and Environmental Engineering, Shenzhen University, Shenzhen 518060, China.E-mail: dingtengda@szu.edu.cn

${ }^{b}$ Dongyang Environmental Protection Monitoring Station, Dongyang 322100, China ${ }^{c} X i l i$ Regenerative Water Plant, Shenzhen Water Group Co. Ltd., Shenzhen 518055, China

$\dagger$ Electronic supplementary information (ESI) available. See DOI: 10.1039/c9ra07263b biochar has a great potential for sequestrating carbon, reducing the emission of greenhouse gases (e.g., methane and nitrous oxides). In addition, biochar can improve the soil fertility and increase the crop yields and productivity. As a readily available and environmental friendly sorbent, biochar showed high potential to uptake and sequester organic contaminants in soil and sediment to prevent the mobility of organic contaminants in soil as well. Excellent removal efficiencies of soil contaminants were obtained by various plant-residue derived biochar. For example, Alizadeh et al. found that soil-softwood-derived biochar efficiently sorbed estrogens. ${ }^{6}$ Mandal et al. found that agro-wastes biochars showed over $89 \%$ of atrazine and imidacloprid adsorption. ${ }^{7}$ Chen and Yuan found that sorption of polycyclic aromatic hydrocarbon (e.g., naphthalene) was enhanced by up to 1170 times after the addition of pine needle biochar in soil. ${ }^{8}$ Jia et al. reported that the post-harvest residue derived biochar was more effective than pure soil in sorbing petroleum pollutants. ${ }^{9}$

Sewage sludge is a growing concern due to its rapid production during wastewater treatments. Up to 10.13 million tons of dry sewage sludge was produced in 2010 in Europe. ${ }^{10}$ Yue et al. indicated that the sewage sludge produced in China has reached 30 million tons each year. ${ }^{11}$ In addition to crop residues, sewage sludge is another important biomass available 
for biochar production. Given that a biochar's sorption capacity varies with the source of biomass, the sorptive behaviors of sewage sludge derived biochars to organic compounds need to be characterized. However, a greater proportion of research on pyrolysis of sewage sludge have focused on energy and fuel quality. ${ }^{12,13}$ Although several studies have considered the effects of sludge-derived biochar on environmental behavior (e.g., bioavailability) of inorganic (e.g., arsenic, cadmium, chromium, cobalt, copper, nickel, lead and zinc) and organic pollutants in soil, ${ }^{14-17}$ to our knowledge few studies have been conducted to ascertain the effect of sewage sludge derived biochar on pesticides applied to agricultural soils and the mechanism was largely unknown.

In this study, a series of biochars were produced by the pyrolysis of sewage sludge under a wide range of temperatures $\left(100-700{ }^{\circ} \mathrm{C}\right)$. Sorption and desorption isotherms of carbendazim by biochars and the raw sewage sludge in soils were compared. Adsorption and partition effects were quantified based on the biochar compositions. The objective of the present study was to understand the effect of sewage sludge derived biochar on soil sorption and desorption of pesticides, exemplified by carbendazim.

\section{Experimental}

\subsection{Carbendazim, biochars, and soil}

Carbendazim (chemical purity: 98\%) was purchased from J \& K Chemical, China. A stock solution of carbendazim was prepared by dissolving it in $\mathrm{N}, \mathrm{N}$-dimethylformamide to arrive at a final concentration of $1000 \mathrm{mg} \mathrm{L}^{-1}$. Soil samples were collected from the top $10 \mathrm{~cm}$ at locations in Cixi, Zhejiang, China. The soils were air-dried, homogenized by sieving $(<1.5 \mathrm{~mm})$ to remove plant debris. The $\mathrm{pH}$ and cation exchange capacity of soil were 7.91 and $6.82 \mathrm{cmol} \mathrm{kg}^{-1}$, respectively. The organic carbon in soil was $0.45 \%$. The ratio of sand, silt, and clay was occupied 12.1, 71 , and $16.9 \%$, respectively. A sample of dewatered sludge was collected from a local wastewater treatment plant (Shenzhen, China). Biochars were produced with a heating rate of $10{ }^{\circ} \mathrm{C} \min ^{-1}$ to different pyrolysis temperatures $\left(100-700{ }^{\circ} \mathrm{C}\right)$ at a continuous purge of $\mathrm{N}_{2}$ for $2 \mathrm{~h}$. The biochars are labeled herein as $\mathrm{BC} 100-\mathrm{BC} 700$ with increasing pyrolysis temperature. The biochars were ground and sieved to less than $1.5 \mathrm{~mm}$. The organic carbon (OC) content of the soil, sludge and biochars was determined by a multi C/N 3100 analyzer (Analytik Jena, Jena, Germany). Other characterization of sewage sludge derived biochars including the element analysis, water soluble metal ions, and specific surface area and pore volume was described in Text S1 in the ESI. $\dagger$

\subsection{Adsorption-desorption experiments}

Adsorption-desorption of carbendazim was measured using a batch equilibrium method at $25^{\circ} \mathrm{C}$. Briefly, an aliquot of $5.0 \mathrm{~g}$ soil (dry weight equivalent) was weighed into a $40 \mathrm{~mL}$ crimp-top glass vial sealed with poly tetra fluoroethylene (PTFE)-lined butyl rubber septa and $25 \mathrm{~mL}$ of $0.01 \mathrm{M} \mathrm{CaCl}_{2}$ solution was added to reach a soil/solution ratio of $1: 5$. Sodium azide
(200 $\mathrm{mg} \mathrm{L}^{-1}$ ) was added into each treatment as a bioinhibitor to prevent the biodegradation of carbendazim during sorption measurements. The soil slurries were spiked with different amounts of carbendazim stock solution to generate nominal concentrations of $1,2,5,10,20$, and $30 \mathrm{mg} \mathrm{L}^{-1}$, respectively. The preliminary experiment showed that a time period of $24 \mathrm{~h}$ was found to be sufficient to establish sorption/desorption equilibrium (Fig. S1 $\dagger$ ), and no chemical degradation of carbendazim or adsorption to the vials was found during the sorption/desorption cycles. The centrifuge tubes were wrapped in aluminum foil and agitated on a shaker at $150 \mathrm{rpm}$ for $24 \mathrm{~h}$. After shaking, three replicates of each treatment were centrifuged at $4000 \mathrm{rpm}$ for $5 \mathrm{~min}$. The supernatants were removed for analysis of carbendazim concentrations in the aqueous phase $C_{\mathrm{e}}\left(\mu \mathrm{g} \mathrm{\textrm {L } ^ { - 1 }}\right)$, whereas the pellets were subjected to desorption. To calculate the carbendazim concentration in the soil phase $C_{\mathrm{s}}\left(\mu \mathrm{g} \mathrm{g}^{-1}\right)$, a soil-free control was included for each treatment. The adsorbed amount $C_{\mathrm{s}}$ of carbendazim was calculated as the difference between the initial concentration and the equilibrium solution concentration $\left(C_{\mathrm{e}}\right)$.

After the sorption experiment, the supernatant was replaced with $25 \mathrm{~mL}$ of carbendazim-free $0.01 \mathrm{M} \mathrm{CaCl}_{2}$ solution. The mixture was then allowed to equilibrate for $24 \mathrm{~h}$ on a shaker. Samples were then centrifuged, filtered, and analyzed as described for sorption experiments.

To discern the influence of biochars, subsamples of soil were mixed with $2 \%$ biochars (BC100-700) (w/w, dry weight). The raw sewage sludge was also used as amendments in the sorption and desorption processes. In addition, the sorption and desorption of carbendazim in soil amended with different rates $(0.5 \%, 1 \%, 2 \%$ and $10 \%)$ of $\mathrm{BC} 700$ or raw sludge were also individually conducted at $25^{\circ} \mathrm{C}$. Samples were then centrifuged, filtered, and analyzed as described above. All experiments were conducted in triplicate.

\subsection{Quantitative determination of carbendazim by UPLC- MS/MS}

The supernatants were filtrated through a $0.22 \mu \mathrm{m}$ Millipore filter and subjected to a Waters ACQUITY ultra high performance liquid chromatography (UPLC) equipped with a micromass triple quadrupole detector (MS/MS) (Xevo-TQD, Waters, Milford, MA) for analysis of carbendazim. More details on UPLC-MS/MS analysis are given in Text S2 in the ESI. $\dagger$

\subsection{Data analysis}

The sorption isotherms were well fitted to the Freundlich model $^{18-20}$ presented as follows:

$$
\log C_{\mathrm{s}}=1 / n \log C_{\mathrm{e}}+\log K_{\mathrm{f}}
$$

where $K_{\mathrm{f}}$ is the Freundlich sorption coefficient $\left(\mu \mathrm{g}^{1-n} \mathrm{~L}^{n} \mathrm{~g}^{-1}\right)$, and $1 / n$ is the degree of isotherm nonlinearity.

The $K_{\mathrm{d}}\left(\mathrm{L} \mathrm{g}^{-1}\right)$ is the linear distribution coefficient for sorption and was calculated by the following equation:

$$
K_{\mathrm{d}}=C_{\mathrm{e}} / C_{\mathrm{s}}
$$


where $C_{\mathrm{s}}$ and $C_{\mathrm{e}}$ are the equilibrium sorbed amounts in the soils and the equilibrium concentration in the solutions, respectively.

The hysteresis index (HI) was used to evaluate the adsorption-desorption hysteresis of carbendazim in soil and soilbiochar mixtures. The equation was listed as follows:

$$
\mathrm{HI}=\left(C_{\mathrm{s}, \text { ads }}-C_{\mathrm{s}, \mathrm{des}}\right) / C_{\mathrm{s}, \mathrm{ads}}
$$

where $C_{\mathrm{s} \text {,ads }}$ and $C_{\mathrm{s} \text {,des }}$ are the sorbed and desorbed amounts ( $\mu \mathrm{g}$ $\mathrm{g}^{-1}$ ) in the soil treatments.

A previous study reported that the main sorption mechanism could be the partition and adsorption effects. ${ }^{21}$ The contribution of two sorption mechanisms could be quantified by an equation $Q_{\mathrm{T}}=Q_{\mathrm{A}}+Q_{\mathrm{P}}=Q_{\mathrm{A}}^{\max }+K_{\mathrm{p}} C_{\mathrm{e}},{ }^{22}$ which the $Q_{\mathrm{T}}, Q_{\mathrm{A}}$ and $Q_{\mathrm{P}}$ represented for the total amount of carbendazim sorbed onto the soil treatments, and the amounts contributed by adsorption and partition, respectively. The $Q_{\mathrm{A}}^{\max }$ is the estimated maximum adsorption capacity of carbendazim by the soil or biochar amended soil. $K_{\mathrm{p}}$ and $C_{\mathrm{e}}$ corresponded to the partition coefficient and the equilibrium concentration of carbendazim, respectively.

\section{Results and discussion}

\subsection{Characteristics of sewage sludge-derived biochars}

The properties of sewage sludge-derived biochars pyrolyzed at different temperatures are presented in Tables 1 and $\mathrm{S} 1 . \dagger$ As a result of the pyrolysis, materials with a more developed surface were obtained compared to the initial sewage sludge. The surface area of sewage sludge derived biochars increased and the pore diameter decreased with increasing pyrolysis temperature. For example, the specific surface area of sewage sludge-based biochar increased from $1.93 \mathrm{~m}^{2} \mathrm{~g}^{-1}$ for BC100 to $45.60 \mathrm{~m}^{2} \mathrm{~g}^{-1}$ for BC700, whereas the pore diameter decreased from $20.22 \mathrm{~nm}$ for BC100 to $8.39 \mathrm{~nm}$ for BC700 (Table 1). The C, $\mathrm{H}, \mathrm{O}, \mathrm{N}$ and cation contents in the raw sewage sludge and biochars decreased with increasing pyrolysis temperature (Table $\mathrm{S} 1 \dagger)$. The molar ratios of $\mathrm{H} / \mathrm{C}, \mathrm{O} / \mathrm{C}$, and $(\mathrm{O}+\mathrm{N}) / \mathrm{C}$ was usually considered indicators for the aromaticity and polarity of biochars. ${ }^{23}$ The pyrolysis of the sludges caused a reduction in the molar ratios of $\mathrm{H} / \mathrm{C}, \mathrm{O} / \mathrm{C}$, and $(\mathrm{O}+\mathrm{N}) / \mathrm{C}$ (Table 1$)$, suggesting that biochars gradually turned to be less hydrophilic. ${ }^{24}$ The lowest $\mathrm{H} / \mathrm{C}$ value (0.05) was found in $\mathrm{BC} 500$, BC600 and $\mathrm{BC} 700$, indicating that they were highly carbonized and had highly aromatic structures. This trend was similar to observations found by Wei et al. that biochar produced at higher temperatures had lower molar $\mathrm{H} / \mathrm{C}$ ratio and higher surface area. ${ }^{25}$

\subsection{Influence of biochars on adsorption-desorption of carbendazim in soils: effect of pyrolysis temperature}

The adsorption-desorption of carbendazim in soils amended with biochars produced at different pyrolysis temperatures were conducted. Approximately $32.3-37.4 \%$ of carbendazim was sorbed by pure soil during the first $2 \mathrm{~h}$ and sorption equilibrium was achieved within $24 \mathrm{~h}$ (Fig. S1 $\dagger$ ), which may be a result of sorptive attenuation processes or a limited capacity of environmental sorption sites for carbendazim. Adsorption and desorption isotherms of carbendazim in the soils with or without biochar amendments were evaluated via the Freundlich
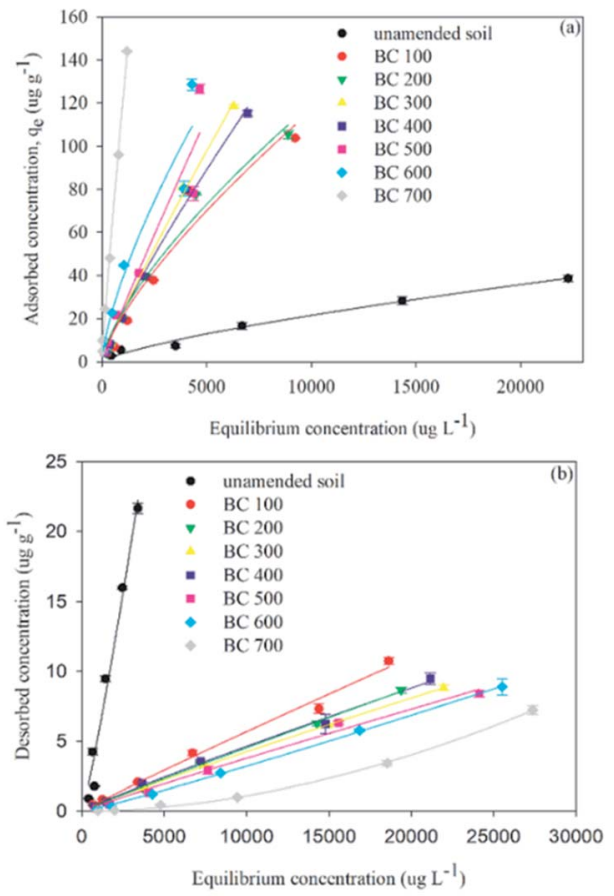

Fig. 1 Carbendazim sorption (a) and desorption (b) isotherms in soil amended with the sludge derived biochar pyrolyzed under different temperatures. Lines are Freundlich-fitted curves.

Table 1 The physio-chemical properties of sewage sludge-based biochars produced at different temperatures. The data with different letters indicate significant differences $(p<0.05)$ among the biochars produced at different temperatures

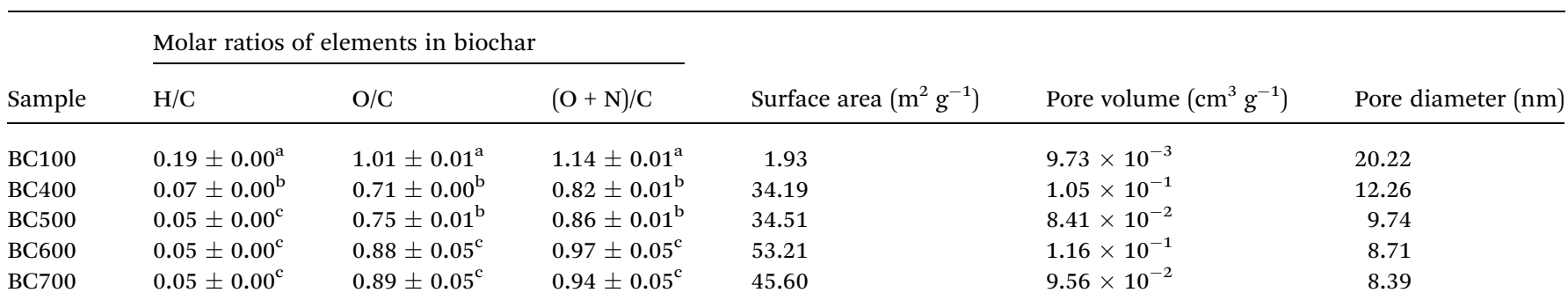


model and a linear model (Fig. 1). The soil without amendments showed low potential for sorption of carbendazim with a $K_{\mathrm{f}}$ value of $0.0239 \mu \mathrm{g}^{1-n} \mathrm{~L}^{n} \mathrm{~g}^{-1}$ and a distribution constant $K_{\mathrm{d}}$ of $0.0019 \mathrm{~L} \mathrm{~g}^{-1}$. The amendments in soil significantly enhanced the adsorption of carbendazim $(p<0.05)$. For example, the $K_{\mathrm{d}}$ value of carbendazim was $0.010 \mathrm{~L} \mathrm{~g}^{-1}$ in soils amended with $2 \%$ raw sludge, which was significantly higher than that in the pure soil. Similarly, the sorption of carbendazim in soils was consistently enhanced by the addition of biochars. The $K_{\mathrm{d}}$ values were increased from $0.0019 \mathrm{~L} \mathrm{~g}^{-1}$ for the non-amended soil to $0.0128 \mathrm{~L} \mathrm{~g}^{-1}$ in soil amended with BC100, which was consistent with the sorption enhancements of carbendazim by superabsorbent polymers. ${ }^{5}$ Generally, the biochar treatments (BC100-BC700) displayed a stronger enhancement on carbendazim adsorption than the sewage sludge treatments. Compared with sewage sludge $\left(0.0112 \mathrm{~L} \mathrm{~g}^{-1}\right)$, the biochar treatments $\left(0.0128-0.1225 \mathrm{~L} \mathrm{~g}^{-1}\right)$, particularly the BC700 $\left(0.1225 \mathrm{~L} \mathrm{~g}^{-1}\right)$, demonstrated a markedly enhancing effect on the adsorption of carbendazim in soil (see Table S2 $\dagger$ ). The organic matter content of raw sewage sludge and biochar amended soil were $29.6 \%$ and $31.8 \%$, respectively, as compared to $0.61 \%$ in un-amended soil. ${ }^{26}$ Therefore, the increased sorption in soil amended with raw sewage sludge or biochar may be attributed to the higher organic matter contents. ${ }^{27}$ As the pyrolysis temperature of biochars increased, the sorption of carbendazim in soil-biochar mixture increased. For example, carbendazim had the highest sorption in soil amended with BC700 with an adsorption efficiency of $98.9 \%$ as compared to $77.0 \%$ in soil amended with BC100 (Fig. S2 $\dagger$ ). Generally, both $k$ and $1 / n$ values affect the sorption isotherm, and the larger the $k$ and $1 / n$ value, the higher the sorption capacity of the sorbents. ${ }^{28}$ The $K_{\mathrm{f}}$ values for carbendazim in biochar-soil mixtures $(0.0478-$ $\left.0.2691 \mu \mathrm{g}^{1-n} \mathrm{~L}^{n} \mathrm{~g}^{-1}\right)$ and raw sludge-soil mixtures $\left(0.0308 \mu \mathrm{g}^{1-n}\right.$ $\left.\mathrm{L}^{n} \mathrm{~g}^{-1}\right)$ were significantly higher than that in pure soil $(0.0239$ $\mu \mathrm{g}^{1-n} \mathrm{~L}^{n} \mathrm{~g}^{-1}$ ), which is consistent with the results reported by Cabrera et al. that the $K_{\mathrm{f}}$ values of herbicides (e.g., fluometuron and 4-chloro-2-methylphenoxyacetic acid) in biochar-soil mixture (13.1 $\mathrm{mg}^{1-1 / n} \mathrm{~L}^{1 / n} \mathrm{~kg}^{-1}$ ) and organo clay-soil mixture $\left(17.2 \mathrm{mg}^{1-1 / n} \mathrm{~L}^{1 / n} \mathrm{~kg}^{-1}\right)$ were higher than that in pure soil $(0.44$ $\left.\mathrm{mg}^{1-1 / n} \mathrm{~L}^{1 / n} \mathrm{~kg}^{-1}\right) .{ }^{29}$ Furthermore, the $K_{\mathrm{f}}$ value for carbendazim in soil amended with BC700 $\left(0.2691 \mu \mathrm{g}^{1-n} \mathrm{~L}^{n} \mathrm{~g}^{-1}\right)$ was approximately 10 orders of magnitude higher than in soil amended with BC300 $\left(0.0478 \mu \mathrm{g}^{1-n} \mathrm{~L}^{n} \mathrm{~g}^{-1}\right)$ and pure soil $\left(0.0239 \mu \mathrm{g}^{1-n} \mathrm{~L}^{n}\right.$ $\left.\mathrm{g}^{-1}\right)$. This finding is inconsistent with the results reported by Yavari et al. that lower adsorption of imazapic was obtained in soil amended with rice husk based biochars produced at higher pyrolytic temperature with $K_{\mathrm{f}}$ value decreased from 4.385 for BC300 to 2.123 for $\mathrm{BC} 700 .^{30}$ Chen et al. also reported that the sorption of polar herbicides was more efficient by biochars produced under lower temperatures $\left(<400{ }^{\circ} \mathrm{C}\right) .{ }^{22}$ It is likely due to the fact that polar compounds are more likely to be influenced by higher oxygenated and polar functional groups of the biochars. ${ }^{31}$ Carbendazim has a low $K_{\text {ow }}\left(\log K_{\text {ow }}=1.5\right)$ and therefore can be considered as a polar compound. However, the higher affinity of carbendazim was observed in soil amended with biochars produced at higher pyrolysis temperature. Similarly, Kearns et al. reported that the $K_{\mathrm{f}}$ value for 2, 4-D was much higher in soil amended with wood chips-based biochar produced at $700{ }^{\circ} \mathrm{C}(8.72)$ than that in soil added with biochar produced at $400{ }^{\circ} \mathrm{C}(0.31) .{ }^{32}$ Chen et al. reported that the surface area and pore volume of sewage sludge-based biochar increased from 48.51 to $73.28 \mathrm{~m}^{2} \mathrm{~g}^{-1}$ and from 0.097 to $0.136 \mathrm{~cm}^{3} \mathrm{~g}^{-1}$ with the pyrolysis temperature increased from 550 to $750{ }^{\circ} \mathrm{C}$, respectively. ${ }^{33}$ In the present study, the surface area and pore volume of sewage sludge-based biochars increased from 1.93 $\mathrm{m}^{2} \mathrm{~g}^{-1}$ and $9.73 \times 10^{-3} \mathrm{~cm}^{3} \mathrm{~g}^{-1}$ for BC100 to $45.60 \mathrm{~m}^{2} \mathrm{~g}^{-1}$ and $9.56 \times 10^{-2} \mathrm{~cm}^{3} \mathrm{~g}^{-1}$ for BC700, respectively. Thus, the stronger sorption of carbendazim in soils amended with biochar producted at higher pyrolysis temperatures may be mainly attributed to the greater surface area and the pore volume of biochars, and the active groups of biochars were not the major factors influencing the sorption of carbendazim.

Desorption isotherms of carbendazim in different soil treatments were also well described by the Freundlich equation, with $R^{2}>0.92$. Carbendazim was gradually desorbed when the equilibrium concentrations of carbendazim increased in all treatments. The desorption isotherm of carbendazim showed that the sorption process of carbendazim was irreversible in soils amended with biochars (Fig. 1b). The desorption concentration of carbendazim in $2 \%$ biochar amended soil was lower than that in raw sewage sludge-soil mixture. For instance, the desorption amounts of carbendazim were 10.75 and $7.23 \mu \mathrm{g} \mathrm{g}^{-1}$, respectively, in soils amended with $2 \% \mathrm{BC} 100$ and $\mathrm{BC} 700$, as compared to the $11.77 \mu \mathrm{g} \mathrm{g}^{-1}$ in $2 \%$ raw sewage sludge-amended soil. However, the highest desorption concentration of carbendazim was found in un-amended soils $\left(21.65 \mu \mathrm{g} \mathrm{g}^{-1}\right)$ (Fig. 1b), indicating the amendments, in particular the biochars, could decrease the desorption capacity of soils. The thermodynamic index of irreversibility (TII) was usually used to quantify the irreversibility in the desorption processes, i.e., TII $=1-n_{\mathrm{ads}} / n_{\mathrm{des}}{ }^{34}$ The TII values ranged from 0 to 1 , with 0 indicating a completely reversible sorption, whereas 1 represented a complete irreversibility. The TII value of carbendazim in un-amended soil was 0.353, whereas in BC100, BC200, BC300, BC400, and BC500-amended soils were 0.232, 0.259, $0.038,0.085$, and 0.003 , respectively, implying that the sorption was more reversible in soils amended with biochar produced at low temperatures $\left(<500{ }^{\circ} \mathrm{C}\right)$. The TII value of carbendazim in BC700-amended soil was determined to be 0.524 (Table S2 $\dagger$ ), indicating that the biochars produced at $700{ }^{\circ} \mathrm{C}$ resulted in an irreversible sorption of carbendazim in soil. Previous studies have reported that the organic amendments (e.g., sewage sludge and humic acid) in soil could limit the transport of pesticide (e.g., methiopyrisulfuron, penconazole) and thus decrease the concentration of pesticides in soil leachates. ${ }^{35,36}$ In the present study, the addition of BC700 facilitated the sorption irreversibility of carbendazim in soil. Sotelo et al. reported that the chemisorption process may be the main mechanism for the sorption of organic molecule onto activated carbon because of the large activation energy, and the chemisorbed species formed a layer over the pore surface to limit the desorption of organic molecule. ${ }^{37}$ Therefore, the BC700 could increase the sorption capacity of carbendazim in soil and limit the release of carbendazim back into the soil. 
The adsorption-desorption hysteresis indexes (HI) of carbendazim with a serial of initial concentrations in soil amended with biochars and raw sludge were presented in Fig. S3. $\dagger$ The HI values were significantly higher in soils amended with biochars and raw sludge than that in pure soil $(p<0.05)$. For example, under the exposure of $30 \mathrm{mg} \mathrm{L}^{-1}$ carbendazim, the $\mathrm{HI}$ increased from $0.44 \pm 0.03$ for un-amended soil to $0.88 \pm 0.003$ in soils amended with $2 \%$ raw sludge and to $0.90 \pm 0.002$ in $2 \%$ BC100soil mixtures. The maximum HI value $(0.99)$ was obtained from the soil-BC700 treatment, indicating that the sorbed carbendazim showed high persistence and was difficult to release back into the sorbent (i.e., BC700-soil mixture). Higher HI values for BC700 indicated the lower desorption rates of chemicals in soil, which was likely due to the stronger immobilization of chemical molecules by enhanced active binding sites or porous structure or pore deformation with the increasing pyrolysis temperature..$^{38,39}$

\subsection{Influence of biochars on adsorption-desorption of carbendazim in soils: effect of application rates}

To better explore the influence of sewage sludge derived biochar on sorption and desorption of carbendazim in soil, different rates of $\mathrm{BC} 700$ were added to the soil and different amount of raw sewage sludge were included as a comparison. The sorption of carbendazim increased with increasing amendment rates of BC700 while kept almost unchanged when different rates of raw sludge was added (Table 2 and Fig. $\mathrm{S} 4 \dagger$ ). For example, the sorbed amount of carbendazim in raw sludge amended soils fortified with $30 \mathrm{mg} \mathrm{L} \mathrm{L}^{-1}$ carbendazim increased slightly from $88.92 \pm 2.47$ to $100.01 \pm 0.69 \mu \mathrm{g} \mathrm{g}^{-1}$ when the amendment rate of sewage sludge increased from $0.5 \%$ to $10 \%$. Accordingly, the $K_{\mathrm{d}}$ values for carbendazim in soil amended with $0.5 \%$ and $10 \%$ raw sewage sludge were $0.0095 \pm 0.00005 \mathrm{~L} \mathrm{~g}^{-1}$ and $0.0119 \pm$ $0.00005 \mathrm{~L} \mathrm{~g}^{-1}$, respectively (Table 2). For biochar treatments, the data clearly indicated that the addition of BC700 enhanced the sorption of carbendazim and the sorption increased when the amendment rates of $\mathrm{BC} 700$ was increased. The sorbed amounts
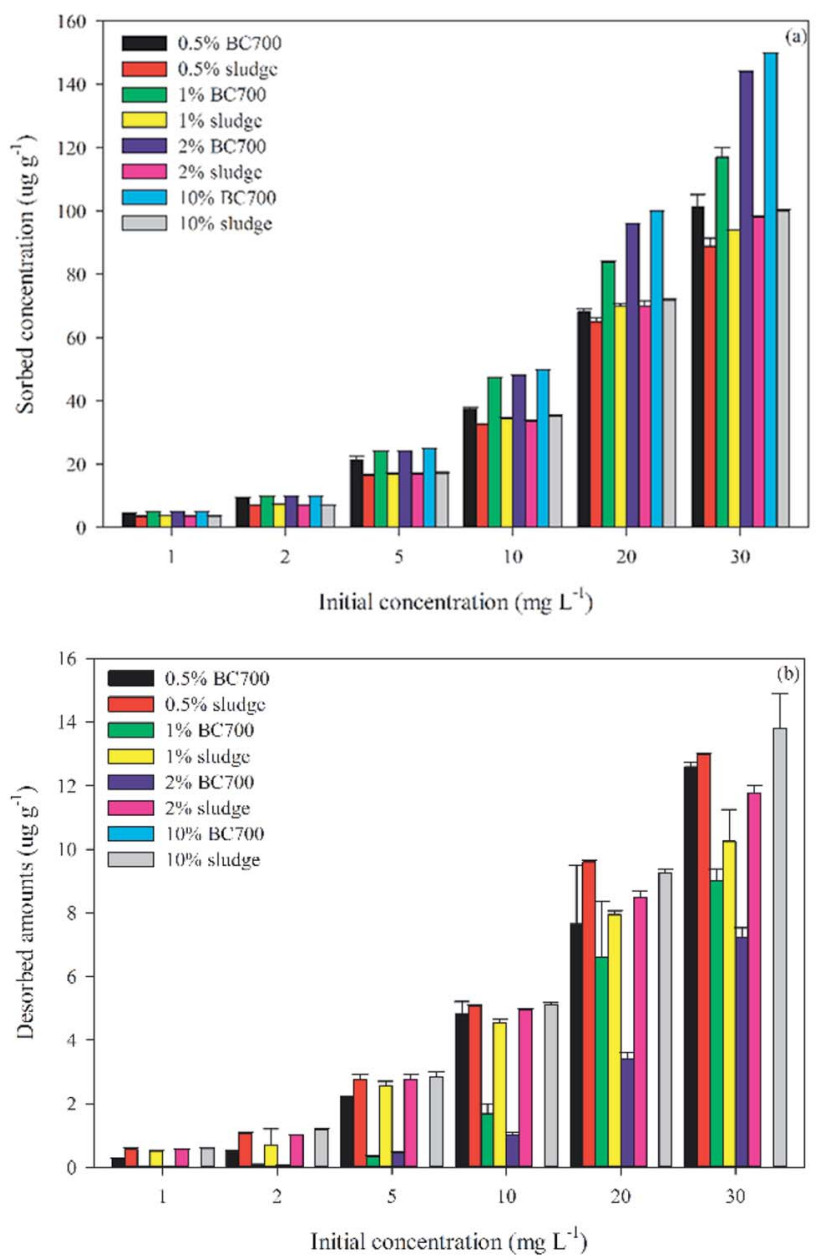

Fig. 2 The adsorption (a) and desorption (b) of carbendazim by BC700 and raw sewage sludge-amended soil at different addition rates.

of carbendazim in BC700-soil mixture increased by $32.5 \%$ as the ratio of BC700 increased from $0.5 \%$ to $10 \%$ (Fig. $2 \mathrm{a}$ ). Similarly, the $K_{\mathrm{d}}$ value for carbendazim in the $10 \%$ BC700 amended soil

Table 2 Adsorption-desorption parameters of carbendazim in soil amended with raw sewage sludge, activated carbon, and biochar with different percentage

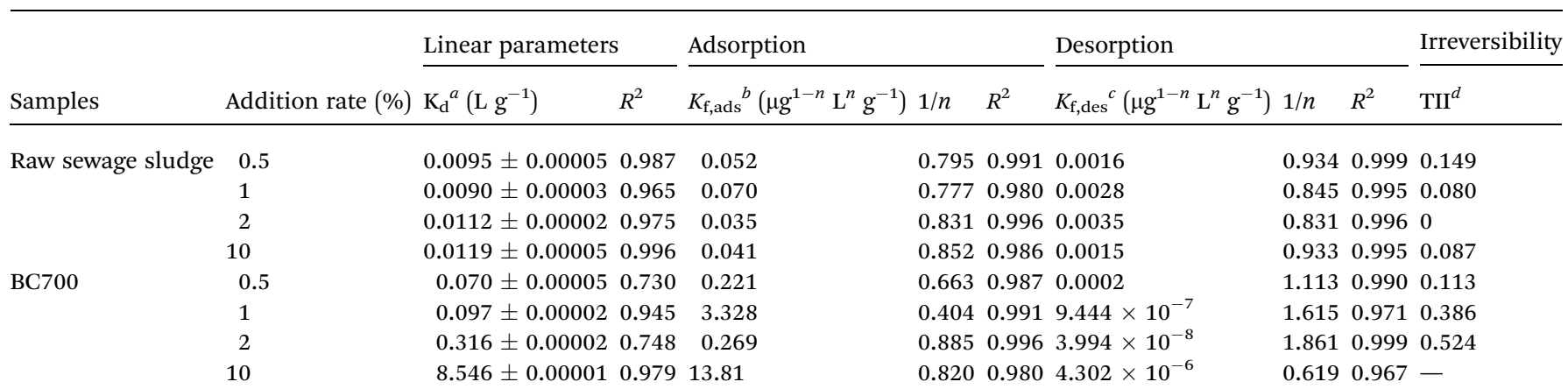

${ }^{a} K_{\mathrm{d}}$ indicated the distribution coefficient for the sorption of carbendazim in soil amended with/without biochar. ${ }^{b} K_{\mathrm{f} \text {,ads }}$ indicated the Freundlich sorption coefficient for the sorption of carbendazim in soil amended with/without biochar. ${ }^{c} K_{\mathrm{f}, \mathrm{des}}$ indicated the Freundlich desorption coefficient for the desorption of carbendazim in soil amended with/without biochar. ${ }^{d}$ TII denoted hysteresis index for adsorption-desorption hysteresis of carbendazim in soil amended with/without biochar. 
(8.546 $\mathrm{L} \mathrm{g}^{-1}$ ) was 122.1 times that in soil amended with $0.5 \%$ of BC700 (0.07 $\mathrm{L} \mathrm{g}^{-1}$ ) (Table 2), implying that the increased amount of biochars could facilitate the sorption of carbendazim in soil. In addition, the sorption of carbendazim in soil amended with BC700 were consistently higher than in soil amended with raw sludge, implying that the addition of biochars, in particular the biochars produced at higher temperature, shower higher sorption capacity than raw sludge. For instance, the sorbed amount in 1\% BC700-soil mixture and 1\% raw sludgesoil mixture spiked with $30 \mathrm{mg} \mathrm{L}^{-1}$ carbendazim was $117.13 \pm$ 3.07 and $93.95 \pm 0.22 \mu \mathrm{g} \mathrm{g}^{-1}$, respectively. When the $2 \%$ BC700 was added to the soil mixed with $30 \mathrm{mg} \mathrm{L}^{-1}$ carbendazim, the sorbed carbendazim concentration in soil increased by $18.7 \%$, but only $4.2 \%$ of increase was observed in soils amended with raw sludge. Fig. 2a was also showed the sorption of carbendazim in soil amended with biochars at different rates. The addition of biochar could significantly improve the sorption as compared to that in soil amended with sludge. It was also indicated that the sorbed carbendazim concentration increased with the initial concentration and the addition rate of biochar increased. Similarly, Deng et al. reported that the sorption of atrazine increased when the addition rates of cassava wastesbased biochars produced at $750{ }^{\circ} \mathrm{C}$ was increased,,$^{40}$ which was likely due to the increased organic carbon and more sorption sites for atrazine introduced by biochars in soil. Khorram et al. also reported that the $K_{\mathrm{f}}$ values in biochar-soil mixtures increased when the percentages of biochars were increased, indicating an enhanced sorption capacity of fomesafen in soils amended with higher rates of biochars. ${ }^{41}$

The desorption of carbendazim in soil amended with BC700 was lower than that in soil amended with raw sludge, especially at high addition rate. Furthermore, the desorbed carbendazim concentration decreased as the addition rate of biochar increased, but no significant difference of desorption was found in soil with different addition rates of raw sludge (Fig. 2b). For instance, when soil was fortified with $30 \mathrm{mg} \mathrm{L}^{-1}$ carbendazim, the desorbed amount was $12.98 \pm 0.029$ and $11.77 \pm 0.257 \mu \mathrm{g}$ $\mathrm{g}^{-1}$ in $0.5 \%$ and $2 \%$ raw sludge-soil mixtures, respectively. In addition, the TII values of carbendazim in raw sludge-amended soil treatments were all lower than 0.15 (Table 2), while it was 0.353 in soils without sludge, implying that the addition of raw sludge resulted in a more reversible sorption of carbendazim in soil. The desorbed amounts of carbendazim in raw sludge-soil mixtures was much higher than that in BC700-soil mixtures (Fig. 2b). For example, when soil was spiked with $30 \mathrm{mg} \mathrm{L}^{-1}$ carbendazim, the desorption concentration in soil amended with $10 \%$ BC700 and 10\% raw sludge was 0.0025 and $13.78 \mu \mathrm{g}$ $\mathrm{g}^{-1}$, respectively. Desorption of carbendazim decreased when the amendment rates of biochar was increased in all biochar treatments. For instance, the TII value of carbendazim in $0.5 \%$, $1 \%$, and $2 \%$ BC700-amended soils were 0.113, 0.386, 0.524, respectively, indicating a transition of reversible to irreversible sorption when the percentages of BC700 was increased. These results were opposite with the results found by Khorram et al. that the desorption capacities of the biochar-amended soils for fomesafen increased as the percentages increased from $0.5 \%$ to $2 \% .^{41}$

\subsection{Possible sorption mechanism of carbendazim in biochar amended soils}

Previous studies have shown that sorption of organic compounds in soils strongly depends on the organic carbon (OC) content of the soil. ${ }^{42-44}$ Consequently, the $K_{\mathrm{d}}$ values in conjunction with OC content of the soil treatments were usually used to calculate the normalized OC partition coefficient $\left(K_{\mathrm{OC}}\right)$. The $K_{\mathrm{OC}}$ values for carbendazim showed an increase trend in soil amended with $2 \%$ of biochars produced at increased temperatures, ranging from $0.049 \mathrm{~L} \mathrm{~g}^{-1}$ in $\mathrm{BC} 100$-amended soil to $0.898 \mathrm{~L} \mathrm{~g}^{-1}$ in BC700-amended soil (Fig. S5a $\dagger$ ), indicating that the pyrolysis temperature played an important role in inducing changes in the organic matter contents of biochars. These values were much lower than those $\left(2.81 \mathrm{~L} \mathrm{~g}^{-1}\right)$ in Hungarian agricultural soil found by Nemeth-Konda et al. ${ }^{45}$ and Vietnamese soils (0.96-2.7 $\mathrm{L} \mathrm{g}^{-1}$ ) reported by Berglöf et al. ${ }^{46}$ Additionally, the $K_{\mathrm{OC}}$ values increased as the amendment rate of biochars was increased. For example, the $K_{\mathrm{OC}}$ was $0.081 \mathrm{~L} \mathrm{~g}^{-1}$ in $0.5 \%$ BC700-amended soil, but it increased to $62.478 \mathrm{~L} \mathrm{~g}^{-1}$ when $10 \%$ of BC700 was added in soil (Fig. S5b $\dagger$ ). These findings indicated that the $K_{\mathrm{OC}}$ values in soil-biochar system was closely correlated to the pyrolysis temperature and the amendment rate of biochar, which may have important implications for the sorption capacity of carbendazim in biochar-amended soils.

The relationship between the $K_{\mathrm{OC}}$ values and sorption capacity of carbendazim with a serial of initial concentrations in soil amended with BC700 was shown in Fig. S6. $\dagger$ Good correlations were consistently observed between the sorbed concentration of carbendazim and the $K_{\mathrm{OC}}$ values for each soil treatment $\left(R^{2}>0.88\right)$, indicating that OC content played a significant role in sorption of carbendazim in soil. It is likely that after the addition of biochars, the changes in the composition of organic matter resulted in a decrease of oxygencontaining functional groups (e.g., carboxyl and hydroxyl) and an increase of specific surface area and pore volume (Table 1). Zielińska and Oleszczuk found that the sorption of phenanthrene and pyrene increased with decreasing proportions of oxygen content after addition of sewage sludge-derived biochar. ${ }^{47}$ Therefore, the decreased oxygen content for biochars produced at higher pyrolysis temperature in the present study may also contribute to the higher affinity or sorption capacity for carbendazim. In general, the correlation $\left(R^{2}\right)$ between soilbiochar mixture and carbendazim was higher in soil treatments spiked with lower concentration of carbendazim, suggesting that the OC content showed greater impact on sorption of carbendazim in soil, especially for soil with lower pollution of carbendazim. The results are consistent with the correlation between two Brazilian tropical soils and $K_{\mathrm{OC}}$ in sorption of carbendazim reported by Carbo et al. ${ }^{48}$ What's more, the $K_{\mathrm{f}}$ of carbendazim in the biochar-soil mixtures had a significant positive correlation with surface area $\left(r^{2}=0.93\right)$, indicating that biochars likely adsorbed carbendazim mainly through hydrophobic effects, pore-filling and $\mathrm{p}(\pi)-\pi$ EDA interactions.

In addition to the adsorption by soil surface via interactions such as ionic bonding and hydrophobic interaction, 
Table 3 Partition coefficients and maximum adsorption of carbendazim in un-amended soil and soil amended with biochar at different temperatures

\begin{tabular}{llll}
\hline Samples & $K_{\mathrm{p}}{ }^{a}\left(\mathrm{~L} \mathrm{~g}^{-1}\right)$ & $Q_{\mathrm{A}}^{\max b}\left(\mu \mathrm{g} \mathrm{g}^{-1}\right)$ & $R^{2}$ \\
\hline BC100 & 0.0116 & 7.33 & 0.908 \\
BC200 & 0.0119 & 8.42 & 0.949 \\
BC300 & 0.0190 & 2.70 & 0.995 \\
BC400 & 0.0168 & 4.04 & 0.987 \\
BC500 & 0.0221 & 3.32 & 0.921 \\
BC600 & 0.0238 & 8.99 & 0.918 \\
BC700 & 0.1157 & 5.92 & 0.999 \\
Un-amended soil & 0.0016 & 3.41 & 0.987
\end{tabular}

${ }^{a} K_{\mathrm{p}}$ was partition coefficient. ${ }^{b} Q_{\mathrm{A}}^{\max }$ was the estimated maximum adsorption capacity.

partitioning into organic matter was reported as another main mechanism for sorption of organic compounds to sediment or soil. ${ }^{22}$ For instance, Hamaker and Thompson reported that the organic matter could provide an important sorbent surface in soil and the hydrophobic interactions between soil and pesticides could induce the phase partitioning. ${ }^{49}$ Wang et $a l .{ }^{42}$ and Urbanczyk et al..$^{50}$ suggested that adsorption and partition were the dominant processes for the sorption of organic compounds (e.g., terbuthylazin, carbendazim, diuron, iodocarb, isoproturon, cybutryn, octylisothiazolinone, terbutryn, and tebuconazole) in sediment/soil-water system. In the present study, the relative contributions of adsorption and partition were quantified via an isotherm-separation method and shown in Table 3 and Fig. S6. $\dagger$ Generally, the partition effect $\left(K_{\mathrm{P}}\right)$ was dominant in the sorption process for carbendazim in the biochar-soil mixtures, while adsorption made a lower contribution to the sorption of carbendazim (Fig. S7†). The relative contributions of adsorption and partition varied in soils amended with biochar produced at temperatures from $100{ }^{\circ} \mathrm{C}$ to $700{ }^{\circ} \mathrm{C}$. The contributions of partition followed the order of unamended soil $<$ BC100 < BC200 < BC300 < BC400 < BC500 < BC600 $<$ BC700, suggesting that the relative contributions of adsorption and partition for sorption of carbendazim are quantitatively influenced by pyrolytic temperature of biochars. The opposite phenomenon was reported by Chen et al. that the sorption mechanism of aromatic contaminants (e.g., naphthalene, nitrobenzene, and $m$-dinitrobenzene) was adsorptiondominant in soil with the addition of pine needles derived biochars at higher pyrolytic temperatures. ${ }^{22}$ Such discrepancy indicated that different source of biochars, regulated by the pyrolytic temperature, could have huge impacts on their adsorptive and absorptive (partition) effects with organic compounds and the sorption mechanism differed between different chemicals.

\section{Conclusions}

In the present study, seven sewage sludge based-biochars produced under different pyrolysis temperatures $\left(100-700{ }^{\circ} \mathrm{C}\right)$ were applied in soil to investigate the adsorption-desorption of carbendazim, the raw sewage sludge was included as a comparison. Both the addition of sewage sludge and sludgederived biochars showed increased sorption capacity of carbendazim in soil. The highest sorption $(98.9 \%)$ of carbendazim was obtained in soil amended with biochar produced at $700{ }^{\circ} \mathrm{C}$. As the amendment rates of $\mathrm{BC} 700$ increased, the sorption capacity of carbendazim increased whereas the desorption capacity decreased, indicating that the addition of biochars enhanced the sorption and inhibited desorption of carbendazim, especially for biochars produced at higher temperature. A good positively correlation between the sorption of carbendazim in biochar-soil mixtures and the $K_{\mathrm{OC}}$ values was observed $\left(R^{2}>0.88, p<0.05\right)$, implying that the soil organic matter played an important role in sorption of carbendazim. Analysis of the sorption mechanism indicated that the partition effect dominated in the sorption processes. This finding may be useful in understanding the distribution and transport of carbendazim in the environment and will be of great significance in remediation strategies for contaminated soil. Field validation experiments will be necessary to ensure that adequate carbendazim removal can be achieved under actual environmental conditions. Additionally, the sewage-sludge derived biochars may be also acted as a fertilizer to apply in the agriculture in the future, and the corresponding criteria for the limits of heavy metal in soil need to be proposed to prevent the secondary pollution by the release of heavy metals from biochars.

\section{Conflicts of interest}

There are no conflicts to declare.

\section{Acknowledgements}

This research was financially supported by the National Natural Science Foundation of China (Grants No. 21607106 and 21777104), the Natural Science Foundation of Guangdong Province (No. 2017A030313226), the Shenzhen Science and Technology Project (Grant No. JCYJ20170818142823471), and the Natural Science Foundation of SZU (Grants 2019027).

\section{References}

1 J. Dijksterhuis, T. Van Doorn, R. Samson and J. Postma, Water, Air, Soil Pollut., 2011, 222, 421-425.

2 B. F. Tollstadius, A. C. G. da Silva, B. C. O. Pedralli and M. C. Valadares, Toxicol. in Vitro, 2019, 58, 78-85.

3 T. S. Andrade, J. F. Henriques, A. R. Almeida, A. L. Machado, O. Koba, P. T. Giang, A. M. V. M. Soares and I. Domingues, Aquat. Toxicol., 2016, 170, 390-399.

4 S. Singh, N. Singh, V. Kumar, S. Datta, A. B. Wani, D. Singh, K. Singh and J. Singh, Environ. Chem. Lett., 2016, 14, 317-329.

5 Y. T. Yang, H. Y. Wang, L. Huang, S. F. Zhang, Y. P. He, Q. Gao and Q. F. Ye, J. Hazard. Mater., 2017, 328, 70-79.

6 S. Alizadeh, S. O. Prasher, E. Elsayed, Z. Qi and R. M. Patel, J. Environ. Sci., 2018, 73, 162-176.

7 A. Mandal, N. Singh and T. J. Purakayastha, Sci. Total Environ., 2017, 577, 376-385. 
8 B. L. Chen and M. X. Yuan, J. Soils Sediments, 2011, 11, 62-71. 9 Y. Jia, Q. Zong, M. Zhang, Z. M. Wang and L. H. Zhang, Bull. Chin. Ceram. Soc., 2016, 35, 815-818.

$10 \mathrm{Millieu/WRc/RPA,} \mathrm{Report} \mathrm{prepared} \mathrm{for} \mathrm{the} \mathrm{European}$ Commission, 2010.

11 Y. Yue, Y. Yao, Q. Lin, G. Li and X. Zhao, J. Soils Sediments, 2016, 17, 763-770.

12 R. Lou, S. B. Wu, G. J. Lv and Q. Yang, Appl. Energy, 2012, 90, 46-50.

13 J. Kim, W. Kim and C. Lee, J. Environ. Sci., 2013, 25, 22722280.

14 H. Lu, W. Zhang, Y. Yang, X. Huang, S. Wang and R. Qiu, Water Res., 2012, 46, 854-862.

15 H. S. Kim, K. R. Kim, Y. S. Ok, Y. K. Lee, B. Kluge, G. Wessolek, W. I. Kim and K. H. Kim, Water, Air, Soil Pollut., 2015, 226, 282.

16 C. Dai, X. Sun, X. Zhou, Y. Zhang and Y. Su, J. Environ. Sci., 2015, 36, 1-8.

17 H. Yao, J. Lu, J. Wu, Z. Lu, P. C. Wilson and Y. Shen, Water, Air, Soil Pollut., 2013, 224, 1370.

18 R. Ahmad and I. Hasan, J. Chem. Eng. Data, 2017, 62, 15941607.

19 I. Hasan and R. Ahamd, Groundwater for Sustainable Development, 2019, 8, 82-92.

20 R. Ahmad and I. Hasan, Groundwater for Sustainable Development, 2017, 5, 75-84.

21 C. T. Chiou and D. E. Kile, Environ. Sci. Technol., 1998, 32, 338-343.

22 B. Chen, D. Zhou and L. Zhu, Environ. Sci. Technol., 2008, 42, 5137-5143.

23 M. Uchimiya, I. M. Lima, K. T. Klasson and L. H. Wartelle, Chemosphere, 2010, 80, 935-940.

24 M. Ahmad, S. S. Lee, X. Dou, D. Mohan, J. K. Sung, J. E. Yang and Y. S. Ok, Bioresour. Technol., 2012, 118, 536-544.

25 L. Wei, Y. F. Huang, Y. L. Li, L. X. Huang, N. N. Mar, Q. Huang and Z. Z. Liu, Environ. Sci. Pollut. Res., 2017, 24, 4552-4561.

26 M. Stefaniuk, P. Oleszczuk and K. Rozylo, Sci. Total Environ., 2017, 599-600, 854-862.

27 L. P. Lou, D. F. Liu, H. Y. Chen, F. Chen, Y. F. He and G. M. Tian, Environ. Sci. Pollut. Res., 2015, 22, 4977-4984.

28 C. Ng, J. N. Losso, W. E. Marshall and R. M. Rao, Bioresour. Technol., 2002, 85, 131-135.

29 A. Cabrera, L. Cox, K. A. Spokas, R. Celis, M. C. Hermosín, J. Cornejo and W. C. Koskinen, J. Agric. Food Chem., 2011, 59, 12550-12560.
30 S. Yavari, A. Malakahmad, N. B. Sapari and S. Yavari, J. Environ. Chem. Eng., 2016, 4, 3981-3989.

31 K. Sun, M. J. Kang, Z. Y. Zhang, J. Jin, Z. Y. Wang, Z. Z. Pan, D. Y. Xu, F. C. Wu and B. S. Xing, Environ. Sci. Technol., 2013, 47, 11473-11481.

32 J. P. Kearns, L. S. Wellborn, R. S. Summers and D. R. U. Knappe, Water Res., 2014, 62, 20-28.

33 H. M. Chen, Y. B. Zhai, B. B. Xu, B. B. Xiang, L. Zhu, L. Qiu, X. T. Liu, C. T. Li and G. M. Zeng, Environ. Technol., 2015, 36, 470-478.

34 M. Sander, Y. Lu and J. J. Pignatello, J. Environ. Qual., 2005, 34, 1063-1072.

35 C. X. Wu, G. Nie, Z. M. Zhang, C. C. Wang, L. M. Gao and J. J. Wang, J. Integr. Agric., 2013, 12, 1589-1597.

36 L. Jiang, J. L. Lin, L. X. Jia, Y. Liu, B. Pan, Y. Yang and Y. Lin, J. Environ. Manage., 2016, 167, 130-138.

37 J. L. Sotelo, G. Ovejero, A. Rodriguez, S. Alvarez and J. Garcia, Chem. Eng. J., 2013, 228, 102-113.

38 H. Zhang, K. Lin, H. Wang and J. Gan, Environ. Pollut., 2010, 158, 2821-2825.

39 F. Sopeña, K. Semple, S. Sohi and G. Bending, Chemosphere, 2012, 88, 77-83.

40 H. Deng, D. Feng, J. X. He, F. Z. Li, H. M. Yu and C. J. Ge, Ecol. Eng., 2017, 99, 381-390.

41 M. S. Khorram, Y. Wang, X. X. Jin, H. Fang and Y. L. Yu, Environ. Toxicol. Chem., 2015, 34, 1258-1266.

42 H. Wang, K. Lin, Z. Hou, B. Richardson and J. Gan, J. Soils Sediments, 2010, 10, 283-289.

43 A. Usyskin, N. Bukhanovsky and M. Borisover, Chemosphere, 2015, 138, 272-280.

44 L. Luo, J. Lv, Z. Chen, R. Huang and S. Zhang, Environ. Pollut., 2017, 231, 1469-1476.

45 L. Nemeth-Konda, G. Y. Fuleky, G. Y. Morovjan and P. Csokan, Chemosphere, 2002, 48, 545-552.

46 T. Berglöf, T. V. Dung, H. Kylin and I. Nilsson, Chemosphere, 2002, 48, 267-273.

47 A. Zielińska and P. Oleszczuk, Bioresour. Technol., 2015, 192, 618-626.

48 L. Carbo, E. L. Martins, E. F. G. C. Dores, C. A. Spadotto, O. L. Weber and E. A. M. De-Lamonica-Freire, J. Environ. Sci. Health, Part B, 2007, 42, 499-507.

$49 \mathrm{~J}$. W. Hamaker and J. M. Thompson, Organic chemicals in the soil environment, Marcel Decker Inc., New York, USA, 1972, vol. 1, pp. 49-144.

50 M. M. Urbanczyk, U. E. Bollmann and K. Bester, Sci. Total Environ., 2016, 573, 639-644. 